\title{
What is it to do good medical ethics? An orthodox Jewish physician and ethicist's perspective
}

\author{
Avraham Steinberg
}

\section{Correspondence to} Dr Avraham Steinberg, Medical Ethics Unit, Shaare Zedek Medical Center, POB 3235, Jerusalem 91031, Israel; steinberg@e-tal.org

Received 23 July 2014 Revised 27 August 2014 Accepted 3 September 2014

\section{ABSTRACT}

This article, dedicated to the 40th anniversary of the Journal of Medical Ethics, approaches the question 'what does it mean to do good medical ethics?' first from a general perspective and then from the personal perspective of a Jewish Orthodox physician and ethicist who tries, both at a personal clinical level and in national and sometimes international discussions and debates, to reconcile his own religious ethical valuesespecially the enormous value given by Jewish ethics to the preservation of human life-with the prima facie 'principlist' moral norms of contemporary secular medical ethics, especially that of respect for patients' autonomy.

\section{MEDICAL ETHICS-BRIEF HISTORICAL BACKGROUND \\ Ancient times}

Since time immemorial, medical ethics deliberations have been expressed in laws, decrees and 'oaths', some of which were prepared for, and usually by, physicians. Among the oldest of these are the Code of Hammurabi in Babylonia, Egyptian papyri, Indian and Chinese writings, the Bible and the Talmud, and early Greek writers, most notably Hippocrates.

\section{Modern times}

In recent times, Thomas Percival's writings, disseminated in 1803 , represent one of the first ethical codes in the USA and the Western world. ${ }^{1}$

Beginning in the second half of the 19th century, medical organisations began writing codes of medical ethics. The first ethics code of the American Medical Association (AMA) was published in $1847 .^{2}$ This was the first modern ethics code of a group of professionals, rather than from an individual physician, that outlined the rights of patients and caregivers. The British Medical Association published its first code of Medical Conduct of Physicians in 1858. The WHO issued the Declaration of Geneva in 1948. This was the first worldwide medical ethics code and was modelled on the Oath of Hippocrates. Many other medical organisations throughout the world have issued medical ethics codes.

\section{Contemporary medical ethics}

Modern medical ethics as a separate field began to develop in the 1950s. One of the major innovations of modern Western medical ethics involves the physician-patient relationship, with the dramatic change from paternalism to autonomy and its resultant requirement for informing the patient, obtaining informed consent, and relating to the patient as an active partner in the decision-making process.

Medical ethics in the narrow historical sense refers to a group of guidelines, such as the Oath of Hippocrates, generally written by physicians, about the physician's ideal relationship to his peers and to his patients. In contrast, modern medical ethics is based on concepts derived from various disciplines, including the biomedical sciences, the behavioural sciences, philosophy, religion and law. Modern medical ethics is essentially a form of 'applied ethics', which seeks to clarify ethical questions that characterise the practice of medicine and biomedical research and to justify and weigh the various practical options and considerations in accordance with ethical theories and principles. Hence, modern medical ethics codes differ from the classic codes by the significant shift away from the narrow physician-oriented perspective to the wider scientific-social outlook.

\section{RECENT MAJOR CHANGES}

The Journal started its way in close proximity to some major, unprecedented advances in health-related sciences, including medicine, as well as significant sociocultural changes, especially in attitudes towards healthcare and healthcare providers, which happened to coincide with and influence some major changes in the perception and practice of medical ethics.

\section{Scientific changes}

In the past 5-6 decades, we have witnessed unprecedented, rapid scientific advances in health-related sciences, such as organ transplantation, lifesustaining and life-prolonging measures, new technological means for procreation, significant genetic discoveries, and the like. Most of these have not only been innovative but almost certainly unimaginable in earlier historic periods.

Along with the great benefits derived from this enormous progress came a range of difficult and challenging ethical dilemmas, not least of which is the huge cost of many of these scientific and technological advances, and the resulting additional need for an adequate ethical response concerning fair distribution of scarce resources and the problems of triage.

\section{Sociocultural changes}

At approximately the same period of time, major sociocultural changes occurred, based on the opportunity for lay people to gain medical
To cite: Steinberg A. J Med Ethics 2015;41:125-128. 
knowledge via mass media, particularly the internet, as well as a general change in attitudes towards authority figures in society. Patients are less submissive to healthcare providers, more argumentative, and very ready to seek second opinions in their search for better medical care.

In addition, at the same time, doctors have been exposed to a much wider involvement of healthcare providers in their treatment of individual patients, and to ever wider involvement of the public at large via the media, courts of law, etc.

These developments have necessitated appropriate ethical attitudes and adjustments in responding to and regulating the different and changing sociocultural demands.

\section{Medical ethics changes}

Thus, medical ethics has dramatically changed since the second half of the 20th century, as it has adjusted to these sociocultural changes, to the range of challenging issues deriving from scientific and technological advances (including problems of scarcity of resources), to the influx of experts from numerous disciplines, and to the great interest of the public at large in this field.

\section{CONCEPTS}

\section{Ethical evaluation}

Ethical acts can be evaluated on four planes: (a) the desire, intent or motivation of the agent; (b) the ethical principles, theories or values involved; (c) the method of analysis; (d) the consequences.

Various ethical teachings emphasise one or more of these planes, and some utilise all four. At times, one needs to consider specific circumstances, which may be temporary or changing, or one needs to find a middle pathway between opposing and contradictory values.

\section{Ethical variety}

There have always existed various ethical schools of thought, with significant differences between them. They differ in the principal justifications and validity of the various ethical theories, as well as in the terminologies, the specific principles and rules, the relative relationship between them, and their practical application.

Ethical norms and regulation may differ from place to place and/or from time to time. For example, in the Hippocratic Oath, we find the following statements: 'I will give no deadly medicine to any one if asked, nor suggest any such counsel; and similarly I will not give a woman a pessary to cause an abortion'. These two important Hippocratic ethical commitments are no longer widely accepted in the modern era.

As to end-of-life decisions, some contemporary ethicists justify giving deadly medicine to certain patients (=active euthanasia), although many still oppose it on ethical grounds; others counsel and suggest lethal drugs to some patients (=physician-assisted suicide), although many still oppose it on ethical grounds; many others accept the use of drugs such as opiates even if they shorten a patient's life provided the physician's intention is to palliate symptoms rather than to shorten life.

As to abortion, some contemporary ethicists defend and support abortion performed directly and intentionally for various reasons, while others oppose it-totally or partially.

In recent years, we have witnessed dramatic changes in ethical principles related to the patient-physician relationship-from extreme paternalism in the past to extreme autonomy in the present. As just indicated, there has been a similarly dramatic change from valuing life as an extreme and even absolute ethical value to viewing autonomy as an over-riding principlethus, for example, moving away from providing continuous lifeprolonging treatments even for dying patients to withdrawing life-sustaining measures, further withdrawing life sustenance, and further hastening death intentionally and directly.

\section{MODERN MEDICAL ETHICS \\ The four principles}

In recent years, several fundamental ethical principles have been formulated and widely adopted as the basis for ethical discussion in medicine: autonomy, non-maleficence (=primum non nocere), beneficence, and justice. ${ }^{3}$

\section{Patient's autonomy}

In modern medical ethics, autonomy has become the over-riding ethical principle, requiring doctors to facilitate any desired action acceptable to a person's own judgment and in accordance with their own choice. The granting of autonomy requires that we recognise and accept the free choice of each person even if that choice seems inappropriate, foolish or even life endangering. Hence, in recent years, the tendency is to make a decision on more and more medical ethical and legal dilemmas according to this principle.

Other ethicists remind doctors that autonomy is only one of several important ethical principles ${ }^{4}$ and that they should not totally abandon other ethical principles regarding physicians' obligations to their patients. Some have formulated 'strong autonomy-weak paternalism' as the most appropriate ethical approach to patient-physician relationships. ${ }^{4}$ Some writers view an overwhelming acceptance of autonomous wishes as ethical anarchy ${ }^{5}$ ! One should also recognise that the Western world's espousal of autonomy is not universally accepted in all societies and cultures, and that the weight to be given to it is culturally dependent. $^{6}$ Ethical duties derived from solidarity and justice may also appropriately restrict autonomy in various circumstances.

\section{Physician's autonomy}

Autonomy is not only the privilege of the patient. It is widely agreed that the physician's autonomy, too, must be respected. A physician may refuse a patient's request for a therapy that has no scientific or rational basis, especially if it may be harmful to the patient. Also, a physician may refuse to implement a patient's decision for a certain treatment or for negating certain treatment if it conflicts with the physician's conscience. In such situations, the physician has the right to forgo treating the patient and to transfer the care to another physician.

\section{SO WHAT DOES IT MEAN TO DO GOOD MEDICAL ETHICS?}

Good medical ethics ought to be built upon the following propositions.

\section{Knowledge and expertise}

Good ethics start with good facts-both factual-scientific and philosophical-legal-cultural-religious. In order to exercise good ethics, one ought to study and continue to study the different ethical positions based on multidisciplinary approaches. This is important in order to comprehend the autonomous wishes of patients from different cultures, religions, attitudes, etc, and thus implement the most appropriate ethical decisions for any particular patient. In my own view, a casuistry approach is much preferred to a principles approach, thus defining the most appropriate ethical discourse and decision-making process for 
each individual patient based on the specific and unique facts and nuances of each case, building up toward the appropriate principles.

Hence, to do good ethics requires experience, knowledge, careful listening to every patient, understanding different cultural-religious viewpoints, and respecting opposing views.

\section{Balancing between opposing values}

In any difficult ethical dilemma, there are two or more values leading to opposing actions and consequences. For instance:

A. Respecting the value of life, even of a dying patient, may lead to actions in favour of continuous life-supporting and life-prolonging measures, whereas respecting the principle of autonomy, particularly in a suffering, dying patient, may lead to withholding or withdrawing life-prolonging measures.

B. Respecting the free choice of the pregnant mother may lead to a decision to interrupt the pregnancy, whereas respecting the independent claim for life of the developing fetus leads to enabling the fetus to be born alive.

C. Respecting autonomy leads to the disclosure of full information to any patient, whereas respecting the principle of do-no-harm leads occasionally to non-disclosure of potentially harmful information to some patients; and so on.

The principle of autonomy ought to be the leading ethical guideline, but it has to be balanced with the following:

A. Responsibility toward the patient, sometimes exercising a paternalistic approach, based on the physician's duty of beneficence and non-maleficence towards his patients.

B. Solidarity toward others, sometimes limiting treatments from an individual patient for the good of others, based on the physician's and society's duty of fair distribution of scarce resources.

C. Operating within societal norms sometimes leads to the denial of certain autonomous wishes of individual patients when these conflict with the appropriate mutually shared societal norms.

D. Taking into account cultural differences, where autonomy in particular circumstances is unacceptable, thus recognising the fact that the value of autonomy is not universally endorsed.

E. Accounting for physicians' autonomy, exempting them from the duty to care for their patients if their autonomous wishes significantly negate the physicians' ethical viewpoint.

\section{Broad involvement}

From a physician's perspective, to do good medical ethics requires primarily to be actively involved with individual patients and healthcare providers, sensitising them to ethical dilemmas, counselling and helping them to analyse the ethical dilemmas, and reaching pertinent and ethically justifiable conclusions.

For those who strive to do good medical ethics on a higher level, clinical and bedside medical ethics is not sufficient. They should also be involved in teaching medical ethics to healthcare providers as well as researching the field and contributing to and sharing with others their personal knowledge and experience.

Nonetheless, even that is not sufficient if one strives to do good medical ethics in its fullest sense. Such an expert ought to be engaged in policy-making-locally, nationally and even internationally. The enormous advances in health-related sciences create ethical dilemmas much beyond individual patient-physician relationships. Many issues require ethical positions in order to formulate public regulations, positions and legislations; hence, experts in medical ethics have a duty to participate in these processes, and to advise and educate the policy-makers in the relevant ethical positions and viewpoints.

\section{PERSONAL PERSPECTIVES}

Being a Jewish Orthodox physician, I strive to strike the balance between a patient's autonomy and other values-primarily sanctity of life-differently from what much modern secular medical ethics proposes.

When a conflict arises between autonomous wishes of a patient regarding the preservation of life or hastening death, I advocate limiting patients' autonomy in well-defined circumstances for the greater moral call of the preciousness of life, beneficence, solidarity and mutually shared values in society.

I attempt to do so in individual patient-physician relationships as well as in society at large via public committees and legislation.

The following are several examples to illustrate the point.

A. I was instrumental in legislating a paragraph in the Israeli Patient's Bill of Rights stating that a statutory institutional ethics committee can enforce life-saving treatment upon a patient despite his refusal, provided that the following is met: adequate explanation is given to the patient; the benefit of the treatment significantly outweighs the negative outcome of the refusal; and the committee has good reasons to assume that the patient will consent post factum. This is a unique approach in Israeli law giving greater weight to the value of life in well-defined circumstances.

B. In end-of-life situations, different end-of-life options are accepted by different national legislations: active euthanasia, physician-assisted suicide, withdrawal of life-support measures, withdrawal of sustenance, withholding further treatment, preserving life by all available means. In the spectrum of choices, the major disputes relate to the relative value of life vis-à-vis quality of life and to patients' autonomy vis-à-vis societal norms. The extreme positions advocate either full respect for autonomy, avoiding almost totally the value of life in the prescribed condition, or full respect of the sanctity of life, avoiding almost totally the notion of autonomy. Most ethicists promote a balance between the two values, striking the line at different points. My own conviction, which is consistent with Orthodox Judaism, is that, in a situation of a fatal, terminal condition entailing pain and suffering, autonomy should be respected to the extent of withholding life-prolonging measures if this is what the patient requests, whereas the sanctity of life should be respected by not performing any act that directly and intentionally hastens death, even if this goes against the patient's wishes. Withholding life-prolonging measures includes the non-initiation of new treatments and the withholding of cyclic treatments, whether this mode of treatment is inherently cyclic (ie, dialysis or chemotherapy) or induced technically (ie, by applying a timer on a respirator which renders the continuous treatment of the respirator into a cyclic form of treatment ${ }^{7}$ ). On the other hand, euthanasia, physician-assisted suicide, and the withdrawal of continuous treatment are regarded as acts that intentionally hasten death and hence are forbidden. This approach was adopted in 2002 by a large committee of 59 members of all walks of life-women and men, Jews and non-Jews, religious and non-religious-as well as professionals of related fieldsphysicians, nurses, social workers, lawyers, philosophers, rabbis-after an intense 2-year debate. The Israeli 
parliament (the Knesset) accepted these conclusions and legislated it as The Dying Patient Act in 2005 after over a year of debates and testimonies by interested parties. This legislative balance is unique to the State of Israel and gives a higher weight to the preciousness of life than in other countries.

C. Saving life is considered to be extremely important by all religions and moral theories. However, in the controversy of organ donations, most ethicists oppose any form of compensation to live donors even though people are dying because of a significant shortage of organs. In my opinion, compensating live organ donors for donating a kidney, if enacted by a government in ways that do not impose unreasonable coercion and thereby save lives, ought to be seriously considered and strictly regulated. I respect arguments against regulated compensation for live organ donors, but reject them on the grounds of the greater moral value of saving lives by increasing the availability of life-saving organs.

D. Finally, in a personal patient-physician relationship, I practise according to the rule of 'strong autonomy-weak paternalism'. Whenever a patient refuses a treatment that in my professional and ethical opinion would be to their benefit, I shy away from accepting their refusal at face value. I make great efforts to try to convince the patient to consent to the treatment, sometimes by involving other professionals and spiritual authorities. Refusals of beneficial treatments are not always clearly autonomous decisions. Sometimes a beneficial treatment is refused because of insufficient information or because of various temporarily impaired states of mind. Hence, paying greater attention to these hindrances indeed brings many patients to consent to and comply with the suggested treatments. This is my way to exercise my duty and responsibility towards my patients while respecting their true autonomy.

Competing interests None.

Provenance and peer review Commissioned; internally peer reviewed.

\section{REFERENCES}

1 Chapman CB. On the definition and teaching of medical ethics. N Engl I Med 1979;301:630-4.

2 Baker R, Caplan A, Emanuel LL, et al. Crisis, ethics, and the American Medical Association 1847 and 1997. JAMA 1997;278:163-4.

3 For in depth discussion, see Beauchamp TL, Childress JF. Principles of biomedical ethics. 7th edn. Oxford, New York: Oxford University Press, 2013; Gillon R, ed. Principles of health care ethics. Chichester: John Wiley \& Sons, 1994.

4 Pellegrino ED, Thomasma DC. For the patient's good. Oxford, New York: Oxford University Press, 1988.

5 Steinberg A. A Jewish perspective on the four principles. In: Gillon R, ed. Principles of health care ethics. Chichester: John Wiley \& Sons, 1994:65-73.

6 Glick SM. Unlimited human autonomy —a cultural bias? N Engl I Med 1997;336:954-6.

7 Ravitsky R. Timers on ventilators. BMJ 2005;330:415. 